\title{
Simultaneous Spectrophotometric Method for Determination of Emtricitabine and Tenofovir Disoproxil Fumarate in Three-Component Tablet Formulation Containing Rilpivirine Hydrochloride
}

\author{
S. Venkatesan and N. Kannappan \\ Department of Pharmacy, Annamalai University, Tamil Nadu 608002, India \\ Correspondence should be addressed to S. Venkatesan; venkatmpharm@rediffmail.com
}

Received 20 May 2014; Accepted 24 October 2014; Published 16 November 2014

Academic Editor: Zsuzsanna Kuklenyik

Copyright (C) 2014 S. Venkatesan and N. Kannappan. This is an open access article distributed under the Creative Commons Attribution License, which permits unrestricted use, distribution, and reproduction in any medium, provided the original work is properly cited.

\begin{abstract}
Developing a single analytical method for estimation of individual drug from a multidrug composition is a very challenging task. A complexation, derivatization, extraction, evaporation, and sensitive-free direct UV spectrophotometric method is developed and validated for the simultaneous estimation of some antiviral drugs such as emtricitabine (EMT), tenofovir disoproxil fumarate (TDF), and rilpivirine $\mathrm{HCl}(\mathrm{RPV})$ in tablet dosage form by Vierordt's method. The solutions of standard and sample were prepared in methanol. The $\lambda_{\max }$ for emtricitabine, tenofovir disoproxil fumarate, and rilpivirine hydrochloride were $240.8 \mathrm{~nm}, 257.6 \mathrm{~nm}$, and $305.6 \mathrm{~nm}$, respectively. Calibration curves are linear in the concentration ranges $4-12 \mu \mathrm{g} / \mathrm{ml}$ for EMT, $6-18 \mu \mathrm{g} / \mathrm{ml}$ for TDF, and $0.5-1.5 \mu \mathrm{g} / \mathrm{ml}$ for RPV, respectively. Results of analysis of simultaneous equation method were analyzed and validated for various parameters according to ICH guidelines.
\end{abstract}

\section{Introduction}

Around 33.4 million people were living with HIV in year 2008 and around 2 million people have died in the same year. Highly active antiretroviral therapy (HAART) has brought new hope for those people who live with HIV/AIDS by decreasing the morbidity and mortality among people infected with HIV. Highly active antiretroviral therapy also has improved the quality of life among the people who live with HIV/AIDS. Combination therapy is preferred to be the gold standard for the treatment of AIDS so as to maximize potency, minimize toxicity, and diminish the risk for resistance development and reduction of pill burden to once-daily dosing so as to optimize the patient's compliance and reduce the treatment costs. The nucleoside reverse transcriptase inhibitors and nonnucleoside reverse transcriptase inhibitors as multidrug combinations are effective in the therapy of human immunodeficiency virus (HIV) infection and are used as a part of highly active antiretroviral Therapy, for the treatment of HIV 1, 2 [1]. The daily regimen containing emtricitabine, tenofovir disoproxil fumarate, and rilpivirine $\mathrm{HCl}$ is virologically and immunologically effective, well-tolerated, and safe with benefits in the lipid profile in the majority of patients (Figure 1) [2]. It is common practice in HIV treatment to give different drugs to the patient. In order to improve the comfort of the daily intake, manufacturers try to combine several active compounds in one dosage form. In this study a UV spectrophotometric method was developed for tablet containing EMT, TDF, and RPV.

Emtricitabine is a nucleoside reverse transcriptase inhibitor (NRTIs). Chemically it is 5-fluoro-1-(2R, 5S)-[2-(hydroxymethyl)-1,3-oxathiolan-5-yl] cytosine. EMT is the enantiomer of thio analog of cytidine which differs from other cytidine analogs, in that it has fluorine in 5 th position.

Tenofovir disoproxil fumarate $\{9-[(\mathrm{R})-2$-[[bis [[isopropoxycarbonyl] oxy] methoxy] phosphonyl] methoxy] propyl] adenine fumarate is a nucleotide analog reverse transcriptase 


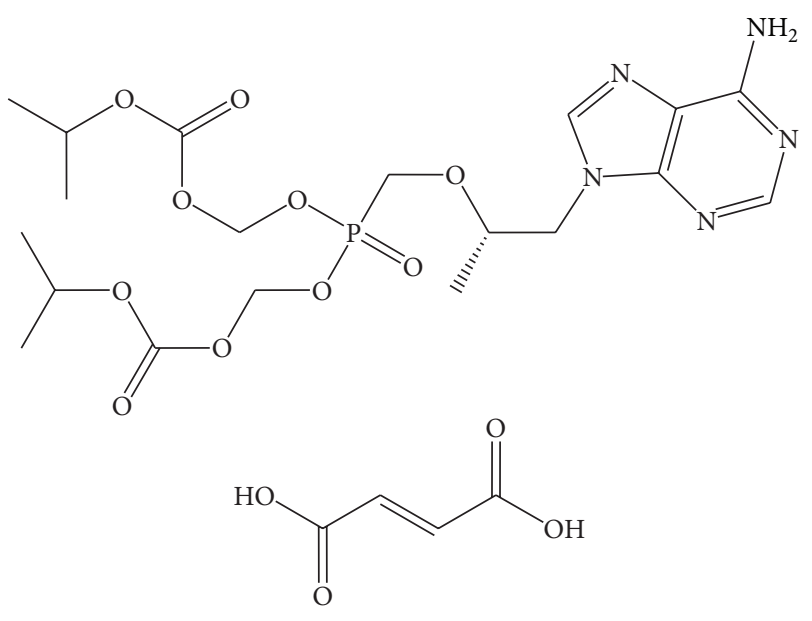

(a) Tenofovir disoproxil fumarate

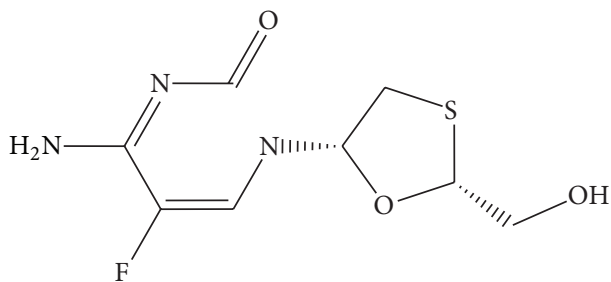

(b) Emtricitabine

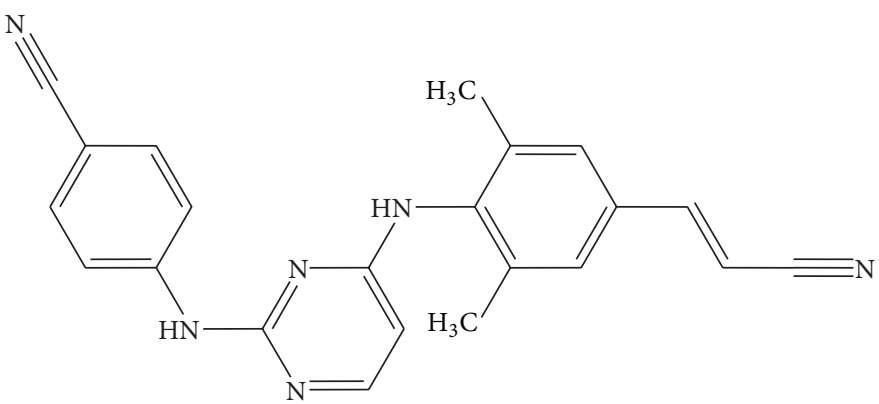

(c) Rilpivirine

FIGURE 1: Chemical structure of (a) emtricitabine, (b) tenofovir disoproxil fumarate, and (c) rilpivirine.

inhibitor (NRTI) and is used for treating HIV infection in adults, in combination with other antiretroviral agents $[3,4]$.

Rilpivirine $\mathrm{HCl}$ chemical name is benzonitrile 4-[[4[[4-[(1E)-2-cyanoethenyl]-2,6-dimethylphenyl]amino]-2-

pyrimidinyl] amino]hydrochloride. It is a second-generation nonnucleoside reverse transcriptase inhibitor (NNRTI) with higher potency, longer half-life, and reduced side effect profile compared with older NNRTIs, such as efavirenz. It is treated with treatment of HIV-1 infection in conjunction with other antiretroviral $[5,6]$.

Literature indicates spectrophotometry [7-13], HPLC [14-17], HPTLC [18], and LC/MS/MS [19] methods for determination of TDF individually and in combination with other drugs in pharmaceutical formulations, drug substance, and biological matrices. Similarly for EMT individually and in combination with other drugs by UV [20, 21], HPLC in pharmaceutical formulations, drug substance and biological matrices [22-27], HPTLC, LC/MS/MS [28], and stability indicating liquid chromatographic methods [29] were reported. A detailed literature survey for RPV revealed that few analytical methods are available using spectrophotometric [30], HPLC [31], and HPTLC [32], individually. Literatures are available to show the existence of HPLC method for the triple drug combination of TDF, EMT, and RPV as well $[5,6]$.

However, no spectrophotometric method has yet been reported for simultaneous estimation of emtricitabine, tenofovir disoproxil fumarate, and rilpivirine $\mathrm{HCl}$ in tablet dosage forms. These methods mentioned in the literature, especially the chromatographic techniques, are time-consuming, costly, and require expertise. A simple and accurate UV spectrophotometric method developed can be highly useful for the routine analysis of tablet formulations. Hence, an attempt has been made to develop and validate in accordance with $\mathrm{ICH}$ guidelines [33].

\section{Objective}

The main objective of the present study is to a develop simple, precise, accurate, and economical analytical method with a better detector range for simultaneous estimation of threecomponent tablet formulation by Vierordt's method and to validate the above method as per the $\mathrm{ICH}$ guidelines.

\section{Experimental}

3.1. Apparatus. A double beam UV-visible spectrophotometer (Shimadzu, 1700), attached to a computer software UV probe 2.0 , with a spectral width of $2 \mathrm{~nm}$ and pair of $1 \mathrm{~cm}$ matched quartz cell, was used.

3.2. Materials and Reagents. Authentic samples of emtricitabine (EMT) and tenofovir disoproxil fumarate (TDF) were kindly provided by Aurobindo Pharma Ltd. (Hyderabad, 


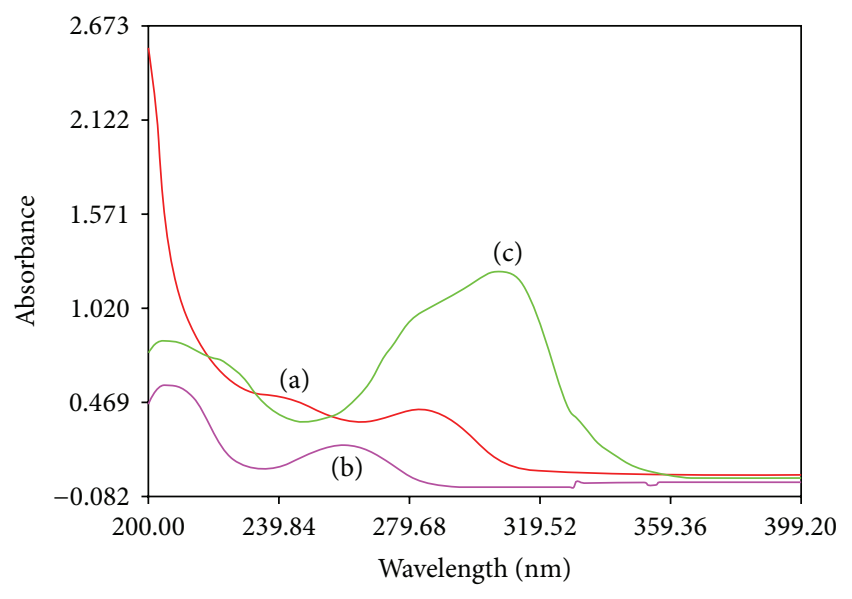

FIGURE 2: Absorption spectra of $10 \mu \mathrm{g} / \mathrm{mL}$ each of EMT, TDF, and RPV in methanol. (a) UV spectrum of EMT; (b) UV spectrum of TDF; (c) UV spectrum of RPV.

India) while rilpivirine $\mathrm{HCl}$ (RPV) was kindly gifted from Strides arco Lab. (Bangalore, India). HPLC grade methanol (S.D fine chemical Ltd., Mumbai, India) was used throughout these experiments. Commercially available tablet dosage forms were assayed in the study Complera/Eviplera Gilead Sciences Inc., Canada, labeled to contain $200 \mathrm{mg}$ EMT, $300 \mathrm{mg}$ TDF, and $25 \mathrm{mg}$ of RPV per tablet.

3.3. Study of Spectra and Selection of Wavelength. $10 \mu \mathrm{g} / \mathrm{mL}$ solution of all three drugs was scanned over the range of 200$400 \mathrm{~nm}$ in $1 \mathrm{~cm}$ cell against blank and the overlain spectra (Figure 2) were observed. While studying the overlay spectra it was observed that EMT shows maximum absorbance at $240.8 \mathrm{~nm}$, TDF shows maximum absorbance at $257.6 \mathrm{~nm}$, and RPV shows peaks at $305.6 \mathrm{~nm}$, respectively. It was observed that there is no interference for each other at absorbance maxima and spectral characteristics are such that all three drugs can be simultaneously estimated by simultaneous equation method [34].

3.4. Standard Solution Preparations. The standard stock solution of EMT, TDF, and RPV was prepared by accurately weighed 20,30 and $2.5 \mathrm{mg}$ of each drug in $10 \mathrm{~mL}$ of volumetric flask separately with methanol. The standard stock solutions were further diluted to get the concentration of 8,12 , and $1 \mu \mathrm{g} / \mathrm{mL}$ of each.

3.5. Calibration Curve. A calibration curve was plotted over a concentration range of $4-12 \mu \mathrm{g} / \mathrm{mL}$ for EMT, $6-18 \mu \mathrm{g} / \mathrm{mL}$ for TDF, and $0.5-1.5 \mu \mathrm{g} / \mathrm{mL}$ for RPV, respectively. For each drug 6 replicates were made by individual weighing (Figure 3 ).

3.6. Simultaneous Equation Method. This method of analysis was based upon the absorption of drugs at wavelength maximum of each other. Three wavelengths of 240.8, 257.6, and $305.6 \mathrm{~nm}$ were selected which are the $\lambda_{\max }$ of three drugs for the development of the simultaneous equations $[35,36]$. The absorbances of EMT, TDF, and RPV were measured and the absorptivity values were determined at all the three selected wavelengths. The concentrations of three drugs in mixture can be calculated using the following equations [37]:

$$
\begin{aligned}
C_{\mathrm{EMT}}= & A_{1}\left(a y_{2} a z_{3}-a z_{2} a y_{3}\right)-a y_{1}\left(A_{2} a z_{3}-a z_{2} A_{3}\right) \\
& +\frac{a z_{1}\left(A_{2} a y_{3}-a y_{2} A_{3}\right)}{a x_{1}\left(a y_{2} a z_{3}-a z_{2} a y_{3}\right)} \\
& -a y_{1}\left(a x_{2} a z_{3}-a z_{2} a x_{3}\right)+a z_{1}\left(a x_{2} a y_{3}-a y_{2} a x_{3}\right) \\
C_{\mathrm{TDF}}= & a x_{1}\left(A_{2} a z_{3}-a z_{2} A_{3}\right)-A_{1}\left(a x_{2} a z_{3}-a z_{2} a x_{3}\right) \\
& +\frac{a z_{1}\left(a x_{2} A_{3}-A_{2} a x_{3}\right)}{a x_{1}\left(a y_{2} a z_{3}-a z_{2} a y_{3}\right)} \\
& -a y_{1}\left(a x_{2} a z_{3}-a z_{2} a x_{3}\right)+a z_{1}\left(a x_{2} a y_{3}-a y_{2} a x_{3}\right), \\
C_{\mathrm{RPV}}= & a x_{1}\left(a y_{2} A_{3}-A_{2} a y_{3}\right)-a y_{1}\left(a x_{2} A_{3}-A_{2} a x_{3}\right) \\
& +\frac{A_{1}\left(a x_{2} a y_{3}-a y_{2} a x_{3}\right)}{a x_{1}\left(a y_{2} a z_{3}-a z_{2} a y_{3}\right)} \\
& -a y_{1}\left(a x_{2} a z_{3}-a z_{2} a x_{3}\right)+a z_{1}\left(a x_{2} a y_{3}-a y_{2} a x_{3}\right),
\end{aligned}
$$

where $C_{\mathrm{EMT}}, C_{\mathrm{TDF}}$, and $C_{\mathrm{RPV}}$ are the concentrations of EMT, TDF, and RPV, respectively, in mixture and in sample solutions.

$A_{1}, A_{2}$, and $A_{3}$ are the absorbances of sample at $240.8,257.6$, and $305.6 \mathrm{~nm}$, respectively,

$a x_{1}, a x_{2}$, and $a x_{3}$ are the absorptivity of EMT at $240.8,257.6$ and $305.6 \mathrm{~nm}$, respectively,

$a y_{1}, a y_{2}$, and $a y_{3}$ are the absorptivity of TDF at 240.8 , 257.6, and $305.6 \mathrm{~nm}$ respectively,

$a z_{1}, a z_{2}$, and $a z_{3}$ are the absorptivity of RPV at 240.8 , 257.6, and $305.6 \mathrm{~nm}$ respectively.

The absorptivity of each solution was calculated by using the following formula [38]:

$$
\text { Absorptivity }=\frac{\text { Absorbance }}{\text { concentration }(\mathrm{gm} / 100 \mathrm{~mL})} \text {. }
$$
lines.

The developed method was validated as per ICH guide-

\section{Results}

4.1. Specificity. Specificity was studied by measuring the absorbance of EMT, TDF, and RPV individually at $240.8 \mathrm{~nm}$, $257.6 \mathrm{~nm}$, and $305.6 \mathrm{~nm}$ against the blank and comparing the absorbance of drugs solutions to the blank. No interference was observed.

4.2. Linearity. Linearity of the proposed method was determined by diluting the stock solution to give concentration range of $4-12 \mu \mathrm{g} / \mathrm{mL}$ for EMT, $6-18 \mu \mathrm{g} / \mathrm{mL}$ for TDF, and $0.5-$ $1.5 \mu \mathrm{g} / \mathrm{mL}$ for RPV. The calibration curve was plotted between concentration verses absorbance (Tables 1, 2, and 3). 


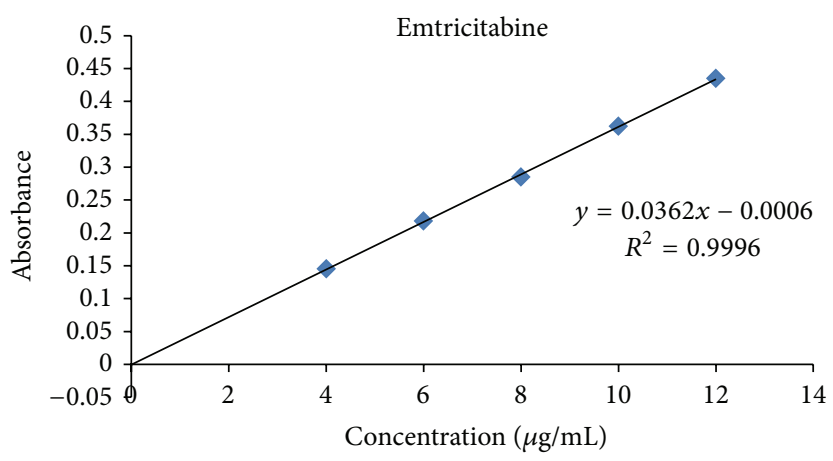

(a)

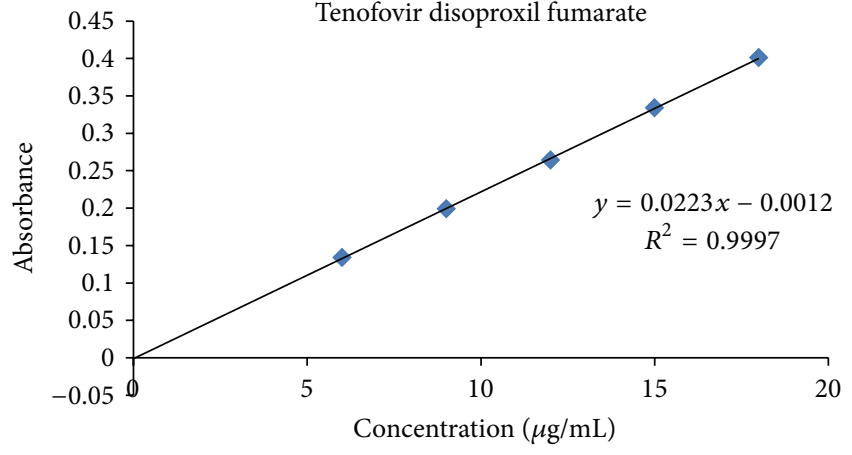

(b)

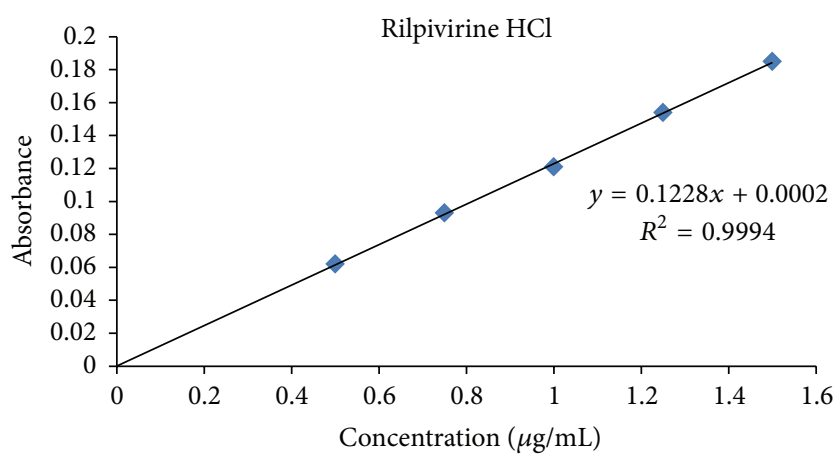

(c)

FIGURE 3: Calibration chart for EMT, TDF, and RPV.

TABLE 1: Absorptivity value for EMT.

\begin{tabular}{lcccccc}
\hline Concentration & Absorbance & Absorptivity & Absorbance & Absorptivity & Absorbance & Absorptivity \\
$\lambda_{1}-240.8$ & $\lambda_{1}-240.8$ & $\lambda_{2}-257.6$ & $\lambda_{2}-257.6$ & 282.5 & 0.028 & $\lambda_{3}-305.6$ \\
\hline 4 & 0.145 & 362.5 & 0.113 & 281.6 & 0.043 & 70.0 \\
6 & 0.218 & 363.3 & 0.169 & 281.2 & 0.057 & 71.6 \\
8 & 0.285 & 356.2 & 0.225 & 281.0 & 0.079 & 71.2 \\
10 & 0.362 & 362.0 & 0.281 & 280.0 & 0.086 & 71.6 \\
12 & 0.435 & 362.5 & 0.336 & 281.2 & Absorptivity for $\lambda_{3}$ & 71.1 \\
\hline
\end{tabular}

TABLE 2: Absorptivity value for TDF.

\begin{tabular}{|c|c|c|c|c|c|c|}
\hline Concentration & $\begin{array}{c}\text { Absorbance } \\
\lambda_{1}-240.8\end{array}$ & $\begin{array}{c}\text { Absorptivity } \\
\lambda_{1}-240.8\end{array}$ & $\begin{array}{c}\text { Absorbance } \\
\lambda_{2}-257.6\end{array}$ & $\begin{array}{c}\text { Absorptivity } \\
\lambda_{2}-257.6\end{array}$ & $\begin{array}{c}\text { Absorbance } \\
\lambda_{3}-305.6\end{array}$ & $\begin{array}{c}\text { Absorptivity } \\
\lambda_{3}-305.6\end{array}$ \\
\hline 6 & 0.134 & 103.3 & 0.062 & 233.3 & 0.000 & 0.000 \\
\hline 9 & 0.199 & 363.3 & 0.169 & 281.6 & 0.000 & 0.000 \\
\hline 12 & 0.264 & 356.2 & 0.225 & 281.2 & 0.000 & 0.000 \\
\hline 15 & 0.334 & 362.0 & 0.281 & 281.0 & 0.000 & 0.000 \\
\hline \multirow[t]{2}{*}{18} & 0.401 & 362.5 & 0.336 & 280.0 & 0.001 & 0.555 \\
\hline & Absorptivity for $\lambda_{1}$ & 361.3 & Absorptivity for $\lambda_{2}$ & 281.2 & Absorptivity for $\lambda_{3}$ & 0.111 \\
\hline
\end{tabular}

4.3. Accuracy. Accuracy was calculated as the percentage recoveries of blind samples of pure EMT, TDF, and RPV and it indicated the agreement between obtained results and those accepted as true, and detailed results are presented in Table 4. To ascertain the accuracy of the suggested methods, recovery studies were carried out by at three different levels (50\%, $100 \%$, and $150 \%$ level).

4.4. Precision. Intraday (within-day) and Interday (betweenday) precision of the proposed methods were determined 
TABLE 3: Absorptivity value for RPV.

\begin{tabular}{lcccccc}
\hline Concentration & $\begin{array}{c}\text { Absorbance } \\
\lambda_{1}-240.8\end{array}$ & $\begin{array}{c}\text { Absorptivity } \\
\lambda_{1}-240.8\end{array}$ & $\begin{array}{c}\text { Absorbance } \\
\lambda_{2}-257.6\end{array}$ & $\begin{array}{c}\text { Absorptivity } \\
\lambda_{2}-257.6\end{array}$ & $\begin{array}{c}\text { Absorbance } \\
\lambda_{3}-305.6\end{array}$ & $\begin{array}{c}\text { Absorptivity } \\
\lambda_{3}-305.6\end{array}$ \\
\hline 0.5 & 0.021 & 420.0 & 0.024 & 480.0 & 0.062 & 1240.0 \\
0.75 & 0.031 & 413.3 & 0.038 & 506.6 & 0.093 & 1240.0 \\
1.0 & 0.041 & 410.0 & 0.049 & 490.0 & 0.121 & 0.154 \\
1.25 & 0.053 & 424.0 & 0.061 & 488.0 & 0.185 & 1210.0 \\
1.50 & 0.062 & 413.3 & 0.072 & 480.0 & Absorptivity for $\lambda_{3}$ & 1232.0 \\
\hline
\end{tabular}

TABLE 4: Recovery studies for EMT, TDF, and RPV.

\begin{tabular}{|c|c|c|c|c|c|c|c|c|c|}
\hline \multirow{2}{*}{ Con $(\%)$} & \multicolumn{3}{|c|}{ Added amount (mg) } & \multicolumn{3}{|c|}{ Amount recovered (mg) } & \multicolumn{3}{|c|}{ Amount recovered (\%) } \\
\hline & EMT & TDF & RPV & EMT & TDF & RPV & EMT & TDF & RPV \\
\hline 50 & 10 & 15 & 1.25 & 9.950 & 15.18 & 1.232 & 99.51 & 101.96 & 98.72 \\
\hline 75 & 15 & 22.5 & 1.875 & 14.99 & 22.66 & 1.874 & 99.94 & 100.75 & 99.94 \\
\hline 100 & 20 & 30 & 2.5 & 20.20 & 29.53 & 2.526 & 101.03 & 98.44 & 101.04 \\
\hline 125 & 25 & 37.5 & 3.125 & 25.14 & 37.64 & 3.062 & 101.27 & 100.38 & 98.00 \\
\hline 150 & 30 & 45 & 3.75 & 30.07 & 44.50 & 3.81 & 100.26 & 98.90 & 101.98 \\
\hline
\end{tabular}

TABle 5: Precision results for EMT, TDF, and RPV.

\begin{tabular}{|c|c|c|c|c|c|c|c|c|c|c|}
\hline \multirow[b]{2}{*}{ Parameter } & \multirow[b]{2}{*}{ Sampling interval } & \multicolumn{3}{|c|}{ EMT } & \multicolumn{3}{|c|}{$\mathrm{TDF}$} & \multicolumn{3}{|c|}{$\mathrm{RPV}$} \\
\hline & & $\begin{array}{c}\text { Amount } \\
\text { present }(\mathrm{mg})\end{array}$ & $\begin{array}{c}\text { Amount } \\
\text { present }(\%)\end{array}$ & \%RSD & $\begin{array}{c}\text { Amount } \\
\text { present }(\mathrm{mg})\end{array}$ & $\begin{array}{c}\text { Amount } \\
\text { present (\%) }\end{array}$ & $\% \mathrm{RSD}$ & $\begin{array}{c}\text { Amount } \\
\text { present (mg) }\end{array}$ & $\begin{array}{c}\text { Amount } \\
\text { present (\%) }\end{array}$ & $\% \mathrm{RSD}$ \\
\hline \multirow{3}{*}{ Within-day } & $0 \mathrm{hrs}$ & 0.1987 & 99.35 & 0.75 & 0.2991 & 99.71 & 0.90 & 0.0250 & 98.94 & 0.67 \\
\hline & $8 \mathrm{hrs}$ & 0.2013 & 100.68 & 0.58 & 0.2970 & 99.03 & 0.54 & 0.0247 & 99.06 & 0.51 \\
\hline & $16 \mathrm{hrs}$ & 0.1996 & 99.84 & 0.37 & 0.2967 & 98.91 & 0.32 & 0.0249 & 99.68 & 0.86 \\
\hline \multirow{3}{*}{ Between-day } & 1st day & 0.1997 & 99.85 & 0.61 & 0.2966 & 98.87 & 0.74 & 0.0251 & 100.48 & 0.87 \\
\hline & 2nd day & 0.1996 & 99.83 & 0.78 & 0.2999 & 99.98 & 0.49 & 0.0249 & 99.71 & 0.89 \\
\hline & 3rd day & 0.1998 & 99.90 & 0.60 & 0.2955 & 98.50 & 0.36 & 0.0250 & 100.03 & 0.57 \\
\hline
\end{tabular}

TABLE 6: Ruggedness results for EMT, TDF, and RPV.

\begin{tabular}{|c|c|c|c|c|c|c|c|c|c|}
\hline \multirow{3}{*}{ Parameter } & \multicolumn{3}{|c|}{ EMT } & \multicolumn{3}{|c|}{ TDF } & \multicolumn{3}{|c|}{ RPV } \\
\hline & \multicolumn{3}{|c|}{ Amount present } & \multicolumn{3}{|c|}{ Amount present } & \multicolumn{3}{|c|}{ Amount present } \\
\hline & $(\mathrm{gm})$ & $(\%)$ & $\%$ RSD & $(\mathrm{gm})$ & $(\%)$ & $\%$ RSD & $(\mathrm{gm})$ & $(\%)$ & $\% \mathrm{RSD}$ \\
\hline Analyst 1 & 0.1995 & 99.79 & 0.65 & 0.2985 & 99.50 & 0.95 & 0.0251 & 100.47 & 0.74 \\
\hline Analyst 2 & 0.2001 & 100.05 & 1.03 & 0.2996 & 99.86 & 1.28 & 0.0250 & 100.25 & 0.98 \\
\hline Instrument 1 & 0.1999 & 99.67 & 0.68 & 0.2981 & 99.38 & 0.79 & 0.0248 & 99.33 & 0.84 \\
\hline Instrument 2 & 0.2000 & 100.04 & 0.85 & 0.2989 & 99.65 & 0.81 & 0.0251 & 100.58 & 0.89 \\
\hline Lab1 & 0.2004 & 100.20 & 0.59 & 0.3000 & 100.0 & 0.58 & 0.0253 & 101.24 & 0.84 \\
\hline Lab 2 & 0.1999 & 99.97 & 0.54 & 0.2977 & 99.26 & 0.84 & 0.0248 & 99.38 & 0.83 \\
\hline
\end{tabular}

by estimating the EMT, TDF, and RPV three times on the same day to obtain repeatability and on three different days to obtain the reproducibility. The results are presented in Table 5.

4.5. Limits of Detection (LOD) and Quantitation (LOQ). They were calculated from the standard deviation (d) of the response and the slope of the calibration curve $(S)$ in accordance with the following equations: $\mathrm{LOD}=3.3(\mathrm{~d} / \mathrm{S})$ and $\mathrm{LOQ}=10(\mathrm{~d} / \mathrm{S})$.

4.6. Ruggedness. A study was conducted to determine the effect of variation in analyst to analyst, lab to lab, and instrument to instrument in triplicate measurements as per the assay method. \% RSD was calculated for each condition and results are presented in Table 6 . 
TABLE 7: Robustness studies (by changing the wavelength).

\begin{tabular}{lcccc}
\hline Analyte & Wavelength $( \pm \mathrm{nm})$ & Amount present $(\mathrm{mg})$ & Amount present $(\%)$ & 100.68 \\
EMT & 239.8 & 0.2001 & 100.60 & 0.72 \\
& 241.8 & 0.2012 & 98.49 & 0.57 \\
\hline \multirow{2}{*}{ TDF } & 256.6 & 0.2954 & 98.78 & 0.36 \\
& 258.6 & 0.2963 & 99.71 & 0.56 \\
\multirow{2}{*}{ RPV } & 304.6 & 0.0249 & 99.01 & 0.68 \\
& 306.6 & 0.0247 & & 0.85 \\
\hline
\end{tabular}

TABLE 8: Stability data of stock solutions.

\begin{tabular}{lcccccc}
\hline & \multicolumn{2}{c}{ EMT } & \multicolumn{2}{c}{ TDF } & \multicolumn{2}{c}{ RPV } \\
DAY & $\begin{array}{c}\text { Amount present } \\
(\mathrm{mg})\end{array}$ & $\begin{array}{c}\text { Amount present } \\
(\%)\end{array}$ & $\begin{array}{c}\text { Amount present } \\
(\mathrm{mg})\end{array}$ & $\begin{array}{c}\text { Amount present } \\
(\%)\end{array}$ & $\begin{array}{c}\text { Amount present } \\
(\mathrm{mg})\end{array}$ & $\begin{array}{c}\text { Amount present } \\
(\%)\end{array}$ \\
\hline 1 & 0.2013 & 100.66 & 0.3002 & 100.07 & 0.0255 & 102.11 \\
2 & 0.2000 & 100.00 & 0.2971 & 99.06 & 0.0256 & 102.41 \\
3 & 0.1992 & 99.64 & 0.2996 & 99.88 & 0.0254 & 101.68 \\
4 & 0.1966 & 98.34 & 0.3508 & 101.95 & 0.0251 & 100.49 \\
5 & 0.2005 & 100.03 & 0.2968 & 99.06 & 0.0244 & 102.41 \\
6 & 0.1989 & 99.64 & 0.2992 & 99.88 & 0.0251 & 101.68 \\
7 & 0.1966 & 98.34 & 0.3504 & 101.95 & 0.0256 & 100.49 \\
\hline
\end{tabular}

TABLE 9: Assay results for commercial formulation.

\begin{tabular}{|c|c|c|c|c|c|}
\hline $\begin{array}{l}\text { Amount present } \\
(\mathrm{mg})\end{array}$ & $\begin{array}{l}\text { Amount present } \\
\text { (\% label claim) }\end{array}$ & $\begin{array}{l}\text { Amount present } \\
(\mathrm{mg})\end{array}$ & $\begin{array}{l}\text { Amount present } \\
\text { (\% label claim) }\end{array}$ & $\begin{array}{c}\text { Amount present } \\
(\mathrm{mg})\end{array}$ & $\begin{array}{l}\text { Amount present } \\
\text { (\% label claim) }\end{array}$ \\
\hline \multicolumn{2}{|c|}{ EMT } & \multicolumn{2}{|c|}{ TDF } & \multicolumn{2}{|c|}{ RPV } \\
\hline 0.2004 & 100.20 & 0.2943 & 98.10 & 0.0251 & 100.61 \\
\hline 0.2032 & 101.60 & 0.2940 & 98.01 & 0.0251 & 100.77 \\
\hline 0.2016 & 100.81 & 0.2951 & 98.38 & 0.0250 & 100.32 \\
\hline 0.1996 & 99.81 & 0.2976 & 99.22 & 0.0256 & 100.41 \\
\hline 0.1989 & 99.46 & 0.2975 & 99.18 & 0.0250 & 100.13 \\
\hline 0.2013 & 100.68 & 0.2968 & 98.94 & 0.0255 & 102.01 \\
\hline S.D & 0.767508 & S.D & 0.543 & S.D & 0.9390 \\
\hline$\%$ RSD & 0.764205 & $\%$ RSD & 0.550 & $\%$ RSD & 0.9293 \\
\hline
\end{tabular}

4.7. Robustness. As per ICH norms, small, but deliberate, variations by changing the wavelength in $\pm 1 \mathrm{~nm}$ from $240.8 \mathrm{~nm}, 257.6 \mathrm{~nm}$, and $305.6 \mathrm{~nm} \mathrm{~nm}$ and the results are presented in Table 7 .

4.8. Stability. The stability of EMT, TDF, and RPV standard and sample working solutions in methanol during handling was verified by keeping them at room temperature for 0 , 8 , and 16 hrs. No significant degradation was observed. The stock solutions were also stable when kept refrigerated at $4^{\circ} \mathrm{C}$ for at least one week and the absorbance of sample solution in each day was measured. Results are presented in Table 8.

4.9. Preparation for Analysis of Tablet Formulation. Twenty tablets were weighed accurately, the average weight of each tablet was determined, and then they were ground to a fine powder. A powder quantity equivalent to $20 \mathrm{mg}$ of EMT, $30 \mathrm{~g}$ of TDF, and $2.5 \mathrm{mg}$ of RPV was transferred to a
$10 \mathrm{~mL}$ volumetric flask and sufficient methanol was added to dissolve it. Then the solutions were sonicated for $15 \mathrm{~min}$. Then final volume was adjusted with methanol and filtered by Whatman filter paper (no. 41). The filtrate was centrifuged at 10,000 RPM for $30 \mathrm{~min}$. Then clear supernatant solutions were transferred to a separate flask without disturbing the sediment. From the clear solution, transfer $0.4 \mathrm{~mL}$ of solution to $100 \mathrm{~mL}$ volumetric flask. Now the tablet sample solution was scanned in multiphotometric mode and the concentration of all three drugs was obtained from the equation. Results of tablet analysis are reported in Table 9.

\section{Discussion}

The proposed method was validated for precision, accuracy, specificity, linearity and range, limit of detection (LOD) and limit of quantitation (LOQ), robustness, and ruggedness. Validation of the proposed method was carried out in 
accordance with the International Conference on Harmonization [33] guidelines. The linearity of the calibration plots was confirmed by the high value of the correlation coefficients $\left(r^{2}=0.9996\right.$ for EMT, 0.9997 for TDF, and 0.9994 for RPV $)$. Recovery was in the range of $98-102 \%$; the values of standard deviation and $\%$ RSD were found to be $<2 \%$ showing the high accuracy of the method. The limit of detection and limit of quantification were theoretically calculated which were found to be 0.1392 and 0.4220 for EMT, 0.226 and 0.685 for TDF, and 0.041 and 0.124 for RPV, respectively. Robustness and ruggedness were also carried out and percentage RSD was found to be less than $2.0 \%$. The assay of EMT, TDF, and RPV was found to be $100.42 \%, 98.63 \%$, and $100.70 \%$. Stability of EMT, TDF, and RPV in methanol was found to be stable up to 7 days at room temperature.

\section{Conclusion}

The Vierordt's method has been successfully applied for simultaneous determination of EMT, TDF, and RPV in combined sample solution, and they were found to be accurate, simple, rapid, and precise. Once the equations were constructed, analysis required only measuring the absorbance values of the sample solution at the selected wavelengths followed by few simple calculations. The proposed method was completely validated showing satisfactory data for all the method validation parameters tested. SE method comparably noted to be very efficient in every aspect. Unlike HPLC, by using Simultaneous equation method (UV) the datas can be generated applying simple calculations. So these methods can be easily and conveniently adopted for routine quality control analysis of these cited drugs.

\section{Conflict of Interests}

The authors declare that there is no conflict of interests regarding the publication of this paper.

\section{References}

[1] A. Rouzes, K. Berthoin, F. Xuereb et al., "Simultaneous determination of the antiretroviral agents: amprenavir, lopinavir, ritonavir, saquinavir and efavirenz in human peripheral blood mononuclear cells by high-performance liquid chromatography-mass spectrometry," Journal of Chromatography B, vol. 813, no. 1-2, pp. 209-216, 2004.

[2] S. Raffanti and D. Haas, Antimicrobial Agents: Anti-Retroviral Agents, McGraw-Hill, New York, NY, USA, 1990.

[3] D. J. Porche, "Tenofovir disoproxil fumarate (Viread)," The Journal of the Association of Nurses in AIDS Care, vol. 13, no. 3, pp. 100-102, 2002.

[4] H. B. Fung, E. A. Stone, and F. J. Piacenti, "Tenofovir disoproxil fumarate: a nucleotide reverse transcriptase inhibitor for the treatment of HIV infection," Clinical Therapeutics, vol. 24, no. 10, pp. 1515-1548, 2002.

[5] K. Y. Kavitha, G. Geetha, R. Hariprasad, R. Venkatnarayanan, and M. Kaviarasu, "Development and validation of RP-UPLC analytical method for simultaneous estimation of the emtricitabine, tenofovir disoproxil fumarate and rilpivirine and its pharmaceutical dosageform," International Research Journal of Pharmacy, vol. 4, no. 1, pp. 150-155, 2013.

[6] D. Pranitha, C. Vanitha, P. Francies et al., "Simultaneous estimation of emtricitabine, tenofovir disoproxil fumarate, and rilpivirine in bulk form by RP-HPLC method," Journal of Pharmacy Research, vol. 5, no. 8, pp. 4600-4602, 2012.

[7] K. Anandakumar, K. Kannan, and T. Vetrichelvan, "Development and validation of emtricitabine and tenofovir disoproxil fumerate in pure and in fixed dose combination by UV spectrophotometry," Digest Journal of Nanomaterials and Biostructures, vol. 6, no. 3, pp. 1085-1090, 2011.

[8] A. A. Atul, H. B. Charashila, and J. S. Sajai, "Application of UVspectrophotometric methods for estimation of tenofovir disoproxil fumarate in tablets," Pakistan Journal of Pharmaceutical Sciences, vol. 22, no. 1, pp. 27-29, 2009.

[9] A. J. Pratap Reddy and I. E. Chakravarthy, "New spectrophotometric determination of tenofovir disoproxil fumaratein bulk and pharmaceutical dosage form," IOSR Journal of Applied Chemistry, vol. 1, no. 2, pp. 29-33, 2012.

[10] T. S. Rani, K. Sujatha, K. Chitra et al., "Spectrophotometric methods for estimation of tenofovir disoproxil fumarate in tablet," Research \& Review: Journal of Pharmaceutical Analysis, vol. 1, no. 1, pp. 9-12, 2012.

[11] J. O. Onah and U. Ajima, "Spectrophotometric determination of tenofovir disoproxil fumarate after complexation with ammonium molybdate and picric acid," International Journal of Drug Development and Research, vol. 3, no. 1, pp. 199-204, 2011.

[12] H. K. Ashour and T. S. Belal, "New simple spectrophotometric method for determination of the antiviral mixture of emtricitabine and tenofovir disoproxil fumarate," Arabian Journal of Chemistry, 2013.

[13] S. Patel, U. S. Baghel, P. Rajesh, D. Prabhakar, G. Engla, and P. N. Nagar, "Spectrophotometric method development Tenofovir disoproxil fumarate and Emtricitabine in Bulk drug and Tablet dosage Form," International Journal of Pharmaceutical and Clinical Research, vol. 1, no. 1, pp. 28-30, 2009.

[14] P. B. Kandagal, D. H. Manjunatha, J. Seetharamappa, and S. S. Kalanur, "RP-HPLC method for the determination of tenofovir in pharmaceutical formulations and spiked human plasma," Analytical Letters, vol. 41, no. 4, pp. 561-570, 2008.

[15] M. E. Barkil, M.-C. Gagnieu, and J. Guitton, "Relevance of a combined UV and single mass spectrometry detection for the determination of tenofovir in human plasma by HPLC in therapeutic drug monitoring," Journal of Chromatography B, vol. 854, no. 1-2, pp. 192-197, 2007.

[16] V. Jullien, J.-M. Tréluyer, G. Pons, and E. Rey, “Determination of tenofovir in human plasma by high-performance liquid chromatography with spectrofluorimetric detection," Journal of Chromatography B, vol. 785, no. 2, pp. 377-381, 2003.

[17] R. W. Sparidans, K. M. L. Crommentuyn, J. H. M. Schellens, and J. H. Beijnen, "Liquid chromatographic assay for the antiviral nucleotide analogue tenofovir in plasma using derivatization with chloroacetaldehyde," Journal of Chromatography B: Analytical Technologies in the Biomedical and Life Sciences, vol. 791, no. 1-2, pp. 227-233, 2003.

[18] M. Joshi, A. P. Nikalje, M. Shahed, and M. Dehghan, "HPTLC method for the simultaneous estimation of emtricitabine and tenofovir in tablet dosage form," Indian Journal of Pharmaceutical Sciences, vol. 71, no. 1, pp. 95-97, 2009.

[19] T. Delahunty, L. Bushman, and C. V. Fletcher, "Sensitive assay for determining plasma tenofovir concentrations by LC/MS/ MS," Journal of Chromatography B, vol. 830, no. 1, pp. 6-12, 2006. 
[20] P. T. Nagaraju, K. P. Channabasavaraj, and P. T. Shantha Kumar, "Development and validation of spectrophotometric method for estimation of emtricitabine in tablet dosage form," International Journal of ChemTech Research, vol. 3, no. 1, pp. 23-28, 2011.

[21] B. Ahindita, P. Aurobinda, K. M. Amit, G. S. Dannana, K. M. Swapna, and C. S. I. Sudam, "Development and validation of spectrophotometric methods for determination of emtricitabine and tenofovir disoproxil fumarate in bulk and tablet dosage form," International Journal of PharmTech Research, vol. 3, no. 3, pp. 1874-1882, 2011.

[22] N. L. Rezk, R. D. Crutchley, and A. D. M. Kashuba, "Simultaneous quantification of emtricitabine and tenofovir in human plasma using high-performance liquid chromatography after solid phase extraction," Journal of Chromatography B: Analytical Technologies in the Biomedical and Life Sciences, vol. 822, no. 1-2, pp. 201-208, 2005.

[23] J. A. H. Droste, R. E. Aarnoutse, and D. M. Burger, "Determination of emtricitabine in human plasma using HPLC with fluorometric detection," Journal of Liquid Chromatography and Related Technologies, vol. 30, no. 10, pp. 2769-2778, 2007.

[24] D. Ashenafi, A. Verbeek, J. Hoogmartens, and E. Adams, "Development and validation of an LC method for the determination of emtricitabine and related compounds in the drug substance," Journal of Separation Science, vol. 32, no. 11, pp. 18231830, 2009.

[25] N. A. Raju and S. Begum, "Simultaneous RP-HPLC method for the estimation of the emtricitabine, tenofovir disoproxil fumarate and efavirenz in tablet dosage forms," Research Journal of Pharmacy and Technology, vol. 1, no. 4, pp. 522-525, 2008.

[26] P. S. Devrukhakar, R. Borkar, N. Shastri, and K. V. Surendranath, "A validated stability-indicating RP-HPLC method for the simultaneous determination of tenofovir, emtricitabine, and a efavirenz and statistical approach to determine the effect of variables," ISRN Chromatography, vol. 2013, Article ID 878295, 8 pages, 2013.

[27] D. S. Bhavsar, B. N. Patel, and C. N. Patel, "RP-HPLC method for simultaneous estimation of tenofovir disoproxil fumarate, lamivudine, and efavirenz in combined tablet dosage form," Pharmaceutical Methods, vol. 3, no. 2, pp. 73-78, 2012.

[28] N. A. Gomes, V. V. Vaidya, A. Pudage, S. S. Joshi, and S. A. Parekh, "Liquid chromatography-tandem mass spectrometry (LC-MS/MS) method for simultaneous determination of tenofovir and emtricitabine in human plasma and its application to a bioequivalence study," Journal of Pharmaceutical and Biomedical Analysis, vol. 48, no. 3, pp. 918-926, 2008.

[29] U. Seshachalam, B. Haribabu, and K. B. Chandrasekhar, "Development and validation of a stability-indicating liquid chromatographic method for determination of emtricitabine and related impurities in drug substance," Journal of Separation Science, vol. 30, no. 7, pp. 999-1004, 2007.

[30] B. G. Bhavar, S. S. Pekamwar, B. K. Aher, and R. S. Chaudhari, "Development and validation of UV spectrophotometric method for estimation of rilpivirine hydrochloride in bulk and pharmaceutical formulations," American Journal of PharmTech Research, vol. 3, no. 1, pp. 450-458, 2013.

[31] S. Ghosh, S. Bomma, L. V. Prasanna, S. Vidyadhar, D. Banji, and S. Roy, "Method development and validation of rilpivirine in bulk and tablet doses form by RP-HPLC method," Research Journal of Pharmacy and Technology, vol. 6, no. 3, pp. 240-243, 2013.

[32] T. Sudha and P. Shanmugasundram, "Reverse phase high performance and HPTLC methods for the determination of rilpirivine bulk and in tablet dosage form," World Journal of Pharmaceutical Research, vol. 1, no. 4, pp. 1183-1196, 2012.

[33] ICH Q2(R1) Guideline, Validation of Analytical Procedures: Text and Methodology, ICH, Geneva, Switzerland, 2005.

[34] P. Giriraj and T. Sivakkumar, "Simultaneous estimation of dutasteride and tamsulosin hydrochloride in tablet dosage form by vierordt's method," Arabian Journal of Chemistry, 2013.

[35] G. H. Jefferey, J. Basset, J. Mendham, and R. C. Denney, Vogels Textbook of Quantitative Chemical Analysis, Longman, London, UK, 5th edition, 1989.

[36] A. H. Beckett and J. B. Stenlake, Practical Pharmaceutical Chemistry, CBS Publishers and Distributors, New Delhi, India, 4th edition, 1997.

[37] R. Sharma and K. Mehta, "Simultaneous spectrophotometric estimation of tenofovir disoproxil fumarate and lamivudine in three component tablet formulation containing efavirenz," Indian Journal of Pharmaceutical Sciences, vol. 72, no. 4, pp. 527530, 2010.

[38] F. Khan, R. T. Lohiya, and M. J. Umekar, “Development of UV spectrophotometric method for the simultaneous estimation of meloxicam and paracetamol in tablet by simultaneous equation, absorbance ratio and absorbance correction method," International Journal of ChemTech Research, vol. 2, no. 3, pp. 1586-1591, 2010. 

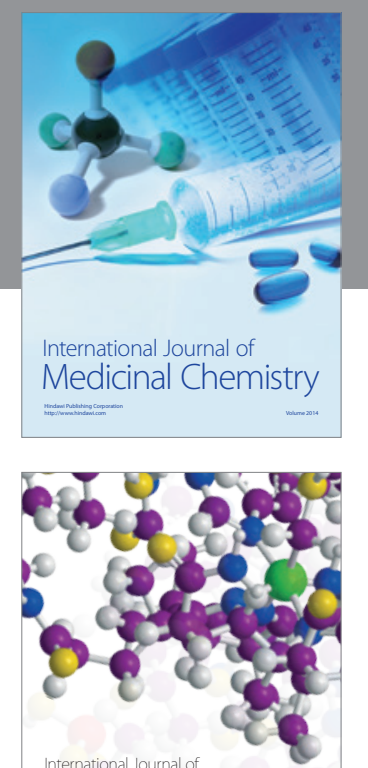

\section{Carbohydrate} Chemistry

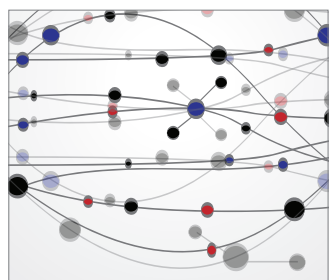

The Scientific World Journal
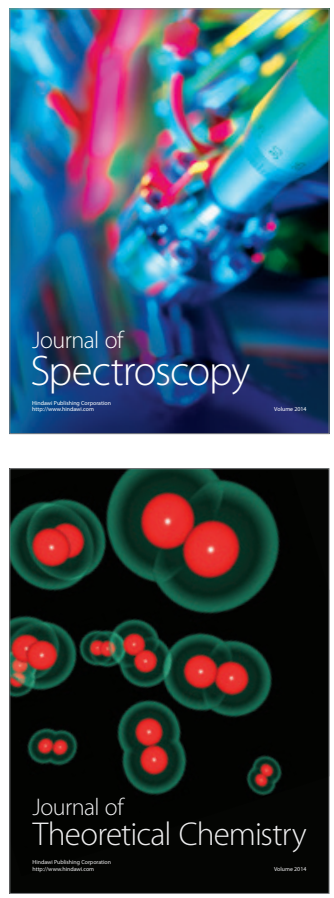
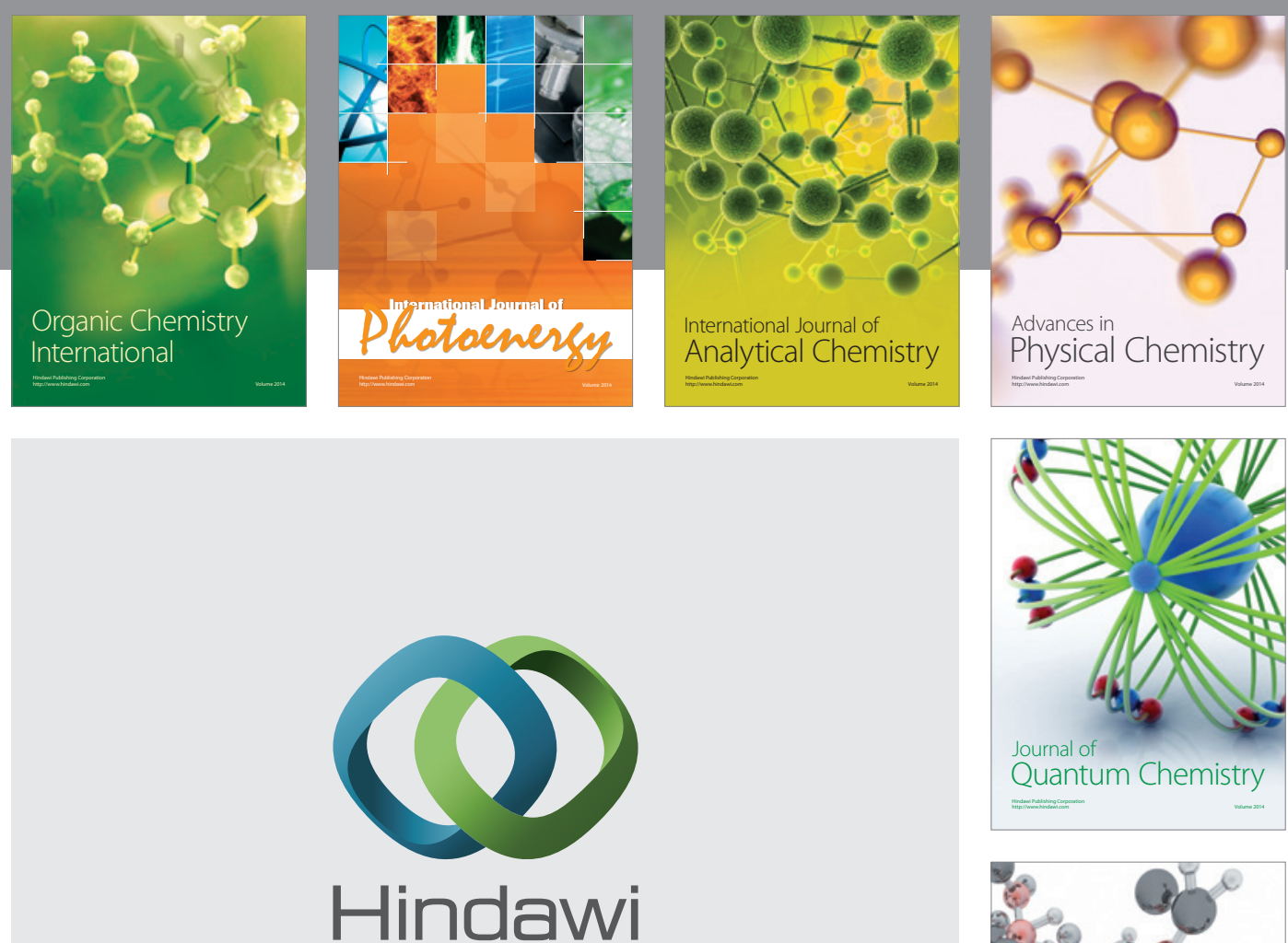

Submit your manuscripts at

http://www.hindawi.com

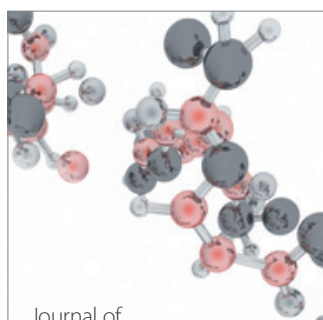

Analytical Methods

in Chemistry

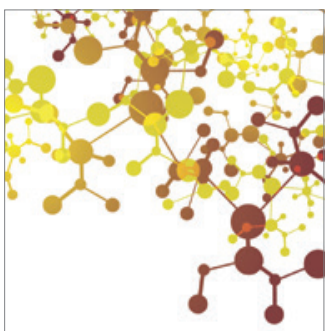

Journal of

Applied Chemistry

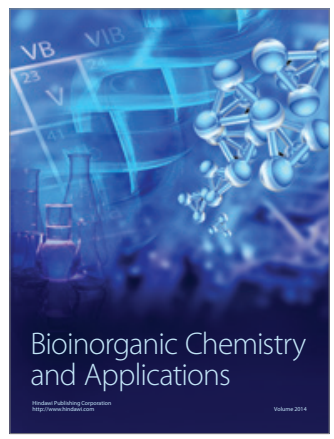

Inorganic Chemistry
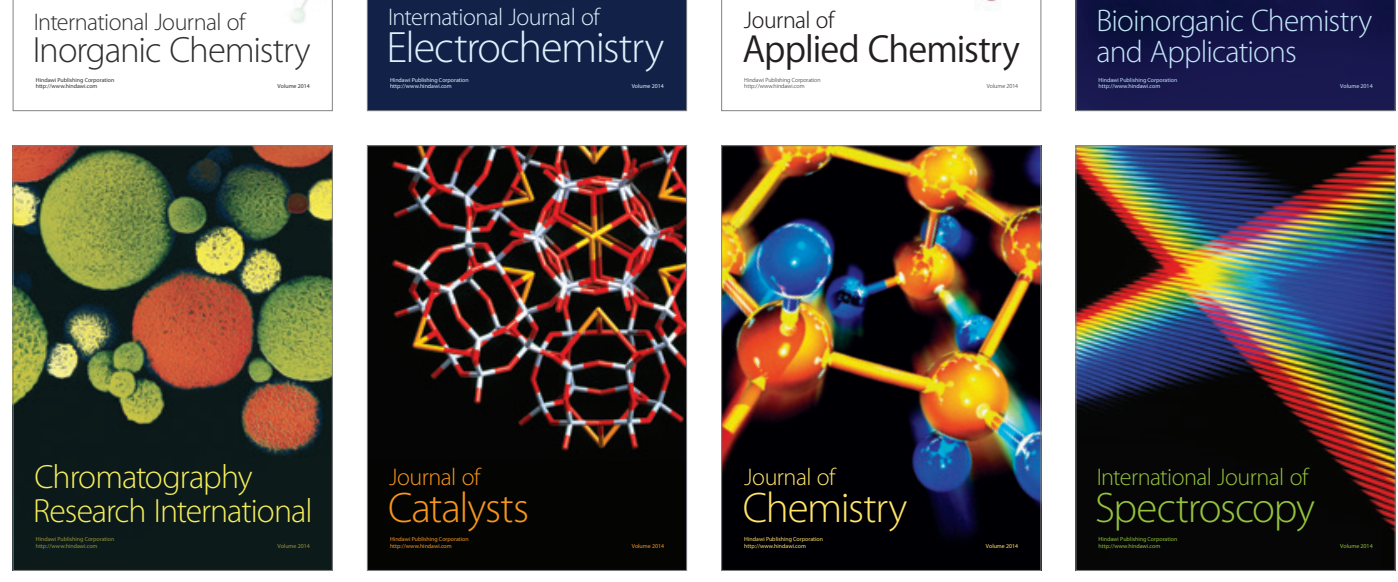